\title{
MedienPädagogik
}

Themenheft Nr. 26: Neue Fernsehserien und ihr Potenzial für eine kritische Medienpädagogik. Herausgegeben von Elena Pilipets und Rainer Winter

\section{Medien der Angst \\ Terrorbildung in den US-amerikanischen Fernsehserien 24 und Sleeper Cell}

Marcus S. Kleiner

\section{Zusammenfassung}

Das Erkenntnisinteresse des Artikels ist darauf gerichtet zu zeigen, wie Populäre Medienproduktionen, hier die fiktionale Fernsehserie, soziale Bilder sowie Diskurse über den Terrorismus transportieren und artikulieren. Hierzu werden die beiden US-amerikanischen Fernsehserien 24 und Sleeper Cell analysiert, die Terror-Bildungsprozesse performativ aufführen: einerseits als US-amerikanische Aussensicht auf den Terrorismus (24), andererseits als Innenansicht einer Terrorzelle (Sleeper Cell). Es handelt sich bei diesen Serien um die ersten Fernsehserien, die die permanente Terror-Bedrohung und Terror-Bekämpfung zum Leitthema machen. Diese beiden Serien sind wegweisend für die verstärkte Auseinandersetzung mit dem Terror in US-amerikanischen Fernsehserien.

\section{Media of the Fear.}

Terror education in the US-American TV serials 24 and Sleeper Cell

\begin{abstract}
In this article it is discussed how popular media productions, here the fictional TV serial, articulate social pictures as well as discourses about terrorism. Moreover both TV serials 24 and Sleeper Cell are analysed. Both perform educational processes in dealing with the terrorism: on the one hand 24 gives an outside view of the terrorism, on the other hand, Sleeper Cell shows an inside view of a terror cell. These both series are the first TV serials, which make the menace by terror and the fight against terror the main theme. These series are ground breaking for the reinforced discussion with the terror in US-American TV serials.
\end{abstract}




\section{Einleitung}

Die weltgesellschaftliche Kollektiv-Angst islamistischer Terrorismus ${ }^{1}$ ist auch fünfzehn Jahre nach 9/11 immer noch ein akutes (welt-)gesellschaftliches Thema und Gegenstand internationaler politischer Kommunikationen. Diese Situation hat sich durch den Zuwachs an islamistischen Terrororganisationen bzw. Terrormilizen nach 9/11, wie z. B. Abu Sajaf, Al Schabab, Boko Haram und den Islamischen Staat (IS), deutlich verschärft.

Das Bundesamt für Verfassungsschutz bezeichnet den Islamismus, insbesondere den islamistischen Terrorismus, als herausragende weltgesellschaftliche Bedrohung. Unter militante Islamisten fasst die Behörde jene Minderheit der Muslime, die das private und öffentliche Leben mit Gewalt nach dem Islam in seiner frühen Ausprägung ausrichten will. Kennzeichnend für militante Islamisten ist die kompromisslos kriegerische Interpretation des Begriffs Dschihad. Wie viele islamistische Terrororganisationen es weltweit gibt, weiss niemand. Dieser Zuwachs und diese Ungewissheit potenzieren die zuvor angesprochene Kollektiv-Angst islamistischer Terrorismus.

Die Weltgesellschaft lässt sich hierbei in unterschiedliche Angstkulturen und -politiken sowie individuelle Angstzustände unterteilen - wobei zumeist aber die Perspektiven der westlichen Welt dominieren. Kollektive Ängste brauchen immer mediale Vermittlungen, um als solche aufgefasst und angeeignet zu werden.

Nichtsdestotrotz irritierte und irritiert der Terrorakt von 9/11, ebenso wie deren Fortführungen in den zahlreichen islamistischen Terrorakten seit 2001, die «symbolische Ordnung» der Weltgesellschaft und «deren Ordnung der Symbole (Twin Towers)», in dem durch den Terror «die - relative Verhaltens- und Erwartungssicherheit konstituierende und sichernde - Erfahrung alltäglicher Normalität» (Hitzler/ Reichertz 2003, 8) zum Einsturz gebracht wurde, zumindest die der amerikanischen Gesellschaft.

Die Anschläge des 11. September 2001 bedeuten zudem, wie Schneckener (2007, 11) hervorhebt, "eine Zäsur in der Geschichte des Terrorismus. Sie sind der dramatische Ausdruck eines «neuen», transnationalen Terrorismus, der sich im Laufe der neunziger Jahre entwickelt hat». Die Bilder des einstürzenden World Trade Centers, das «Sinnbild des «Any thing goes〉 des technischen Fortschritts» und der «Inbegriff des American Way of Life» (Buttler 2003, 31), wurden zu Ikonen eines neuen Clash of Cultures und weltpolitischen Machtkampfes. Terror-Deutung, Terror-Bewältigung und die Schaffung einer neuen symbolischen Ordnung werden

1 Meiner Analyse liegt die Terrorismus-Definition von Hitzler/Reichertz $(2003,8)$ zugrunde: «Terror soll heißen die absichtliche, angekündigte oder unangekündigte, mit instrumentellen und/oder symbolischen Mitteln erzeugte Verbreitung von Schrecken durch alle Arten von kollektiven und individuellen Akteuren gegenüber bestimmten Personen, Personengruppen oder jedermann, - in einem (von den potentiellen Adressaten) nicht vorherseh-, erwart- und kalkulier- bzw. kontrollierbaren Ausmaß.» [Hervorhebung im Original - MSK]. 
hierbei nicht nur von Politik und Gesellschaft geleistet, sondern auch Medienfiktionen beteiligen sich intensiv an dieser Arbeit.

«[N]ach dem Terror» muss «der Terror selbst gedeutet und in die symbolische Ordnung einer Gesellschaft eingearbeitet und eine neue Ordnung der Symbole errichtet werden» (Hitzler/Reichertz 2003, 8). ${ }^{2}$ Diese soziale Gewöhnung an den Terror, die zunächst und zumeist auf eine für die meisten abstrakte Terror-Bedrohung rekurriert, scheint, neben der journalistischen Aufarbeitung, gerade im Rahmen der Medienunterhaltung besonders greifbar zu werden. Das ist naheliegend, denn Terrorismus ist nicht nur Gewaltausübung, sondern ebenso ein demonstratives Kommunikationsprogramm (Artikulation), das Anschlusskommunikationen durch Medialisierung intendiert (Wahrnehmung) und eine möglichst umfassende Verbreitung seines Zeichen-Setzens und Zeichen-Produzierens. Schuster (2001) hebt in diesem Kontext eine Transformation der Medien, allerdings mit Blick auf Nachrichtenmedien und die Berichterstattung über die Ereignisse von 9/11, hervor:

Die Terroristen [...] funktionieren Medien gezielt zu Waffen um. Kommunikationsmittel fungieren ihnen als Kanonen, mit denen sie auf das Bewusstsein der Menschen zielen. [...] Die globale Tragweite des Terrorangriffs folgt aus seiner bösartigen, doch durchschlagenden Simplizität: Die Attacke erfolgte im Zentrum der globalen Medienindustrie und traf die meistgefilmten Symbole amerikanischer Macht. Die Piloten des Terrors wussten, ihr Angriff würde vor laufenden Kameras stattfinden.

Die Umfunktionierung der performativen Aufführung von Terror und Terrorbekämpfung in fiktionalen Medienformaten transformiert diese Transformation ihrerseits, indem sie den Terrorereignissen und den Medienstrategien der Terroristen eine spezifische medienkulturelle Interpretation mit politischen oder ideologischen Implikationen verleiht, die ebenso Einfluss auf die Aneignungsprozesse nehmen möchte.

Der gesellschaftliche Kampf um Bedeutung wird in (populären) Medienkulturen wesentlich als ein Kampf um Bilder und die Deutungsmacht über Bildproduktionen geführt, bei dem der Terror im Spannungsfeld von aisthesis und Ästhetik eine eigensinnige Sinn(es)bildung erhält: «Bilder liefern [...] eine Vergewisserung der Realität, sie zeigen augenscheinlich das, was wirklich ist, und damit werden wir dessen gewiss, was zu tun ist, wie wir auch emotional darauf reagieren und was wir im Weiteren zu tun haben» (ebd.). Das Resultat sind Bilder des Terrors, die schnell zum Terror der Bilder (vgl. Stiglegger 2010) werden. Der Terrorismus ist aber auch immer an bestimmte Vorstellungen gebunden, an spezifische Terrorbilder, besitzt also gleichwohl eine manifeste symbolische Bedeutung.

2 Die gesellschaftliche, kulturelle und mediale Terrordeutung adressiert, wie Hitzler/Reichertz (2003, 9) hervorheben, v. a. drei Problemfelder: «Verhinderung und Milderung weiteren Terrors», "Gesellschaftliche (Neu-)Deutung von Terror», «Schaffung und Festigung einer neuen Ordnung der Symbole». 
(Populäre) Medienkulturen, hier Fernsehserien (vgl. u. a. Flynn/Salek 2012; Takacs 2012, Däwes et al. 2015) führen hierbei performativ Terror-Bildungsprozesse und Terror-Pädagogiken auf. Die Bedeutung des Fernsehens im Kontext von (Selbst-) Bildungsprozessen im Umgang mit dem Terrorismus besteht v. a. darin, dass das Fernsehen zum einen ein Medium kultureller Selbstverständigung ist bzw. ein «kulturelles Forum» (Newcomb/Hirsch 1986).

In diesem Beitrag analysiere ich zwei US-amerikanische Fernsehserien, $24^{3}$ und Sleeper Cell, die Terror-Bildungsprozesse performativ aufführen: einerseits als USamerikanische Aussensicht auf den Terrorismus (24), andererseits als Innenansicht einer Terrorzelle (Sleeper Cell). Es handelt sich bei diesen Serien um die ersten zwei US-amerikanischen Fernsehserien, die die permanente, nicht nur islamistische, Terror-Bedrohung und Terror-Bekämpfung zum Leitthema machen. Diese beiden Serien sind wegweisend für die verstärkte Auseinandersetzung mit dem Terror in US-amerikanischen Fernsehserien. Beide Serien sind medienkulturelle Urszenen im Umgang mit dem (islamistischen) Terrorismus, ebenso wie 9/11 eine weltgesellschaftliche Urszene für den islamistischen Terrorismus darstellt - ohne hiermit die Bedeutung beider gleichzusetzen. Auch 15 (24) und 11 Jahre (Sleeper Cell) nach Serienstart besitzen diese Serien hohe Aktualität. Die medienkulturelle und gesellschaftliche Auseinandersetzung mit dem Terror, v. a. mit dem islamistischen, hat sich nicht wesentlich verändert, nur ausdifferenziert und intensiviert. Ohne 24 und Sleeper Cell wären Terror-Serien wie, um nur das aktuell prominenteste Beispiel zu nennen, Homeland (vgl. hierzu u. a. Arp 2016), nicht möglich gewesen. ${ }^{4}$

Ich werde mit einer heuristischen Kontextualisierung des Themas Bildung und Medienbildung beginnen (Kap. «Bildung und Medienbildung»). Dies schafft die Basis für meine Analyse von 24 (Kap. «24») und Sleeper Cell (Kap. "Sleeper Cell»). Ich beziehe mich hierbei auf einige repräsentative Leitmotive der 2. Staffel von 24 und der 1. Staffel von Sleeper Cell. Mein Erkenntnisinteresse ist darauf gerichtet zu zeigen, wie populäre Medienproduktionen, hier die fiktionale Fernsehserie, soziale Bilder sowie Diskurse über den Terrorismus transportieren und artikulieren. Abschliessend werde ich meine Überlegungen mit einem kurzen Ausblick auf das Terror-Bildungskapital von 24 und Sleeper Cell (Kap. «Fazit. Terror-Bildung und Terror-Pädagogik im Zeichen der Angst»).

3 Zudem erschien noch der Fernsehfilm 24 Redemption und die 12-teilige Fernseh-Miniserie 24 - Live Another Day, die auch als neunte Staffel wahrgenommen wird.

4 Weitere repräsentative TV-Terror-Serien sind: The Unit, Strike Back, Person of Interest, American Odyssey und Designated Survivor. 


\section{Bildung und Medienbildung}

Populäre Medienkulturen sind kontingente Wahlgemeinschaften, die zeitbedingte Manifestationen von sozialen und kulturellen Prozessen darstellen, diese medialisieren, als Text, Bild, Ton usw., soziale und kulturelle Erfahrungen hierbei aufführen, Medienerfahrungen präsentieren, diese zu Medienereignissen und Aneignungserlebnissen machen, die in Lebenswelten überführt werden (können), und dabei (potenziell) performative (Selbst-)Bildungsräume eröffnen. Selbstbildung ist nur durch den Bezug auf ein Aussen (Welt und Andere) möglich und ist daher nicht auf das Selbst als Erfahrungsraum reduziert, weil so keine Transformationen stattfinden könnten. Wimmer $(1996,137)$ betont in diesem Kontext, dass die

Idee der Bildung die Forderung nach einem Bezug zum Außen, der die Singularität nicht nivelliert, [...] die das Subjekt also nicht mit dem Allgemeinen vermittelt und als Singularität aufhebt, sondern in Bezug zum Anderen und damit zur Forderung nach Gerechtigkeit bringt.

Dabei ist die Frage, was Bildung innerhalb dieser Kulturen bedeutet, nicht von der Frage zu trennen, welche bildende Funktion die Medien potentiell besitzen und sich mit ihrer Bildungsfunktion selbst bilden. Bildung ist zugleich Medienbildung, ebenso wie Kultur immer auch Medienkultur ist. Hierbei muss auch gefragt werden, zu welchen Selbstbildungsprozessen populäre Medienkulturen beitragen (können).

Bildung verstehe ich mit Kokemohr grundsätzlich als einen Transformationsprozess:

Bildung [ist] der Prozess der Bezugnahme auf Fremdes jenseits der Ordnung [...], in deren Denk- und Redefiguren mir meine 〈Welt se gegeben ist. Widerständige Erfahrungen können in Texten, Bildern oder anderen Formen auftreten. Von Bildung zu sprechen sehe ich dann als gerechtfertigt an, wenn der Prozess der Be- oder Verarbeitung subsumtionsresistenter Erfahrung eine Veränderung von Grund legenden Figuren meines je gegebenen Welt- und Selbstentwurfs einschließt. (Kokemohr 2007, 21)

Bildung als Transformationsprozess, der auf ein vom Subjekt ausgehendes Selbstund Weltverhältnis bezogen ist, bedeutet eine eigensinnige Haltung zum und eine selbstbestimmte Modifikation des Bildungskanons der Dominanzkultur, bei der nichts ausser Frage steht und nichts unbedingte Gültigkeit für sich in Anspruch nehmen kann. Bildung wird als ein unabschliessbarer Werdensprozess aufgefasst, der mehr Verunsicherung erzeugt, als Gewissheiten anbietet. Der Weg von Bildungsprozessen geht vom Bestimmten (Wissen) zum Unbestimmten (zum flexiblen Umgang mit dem Wissen).

Kokemohr (2007) geht nicht mehr von der Konzeption eines selbstreferenziellen autonomen Subjekts aus, dies verbindet seine Überlegungen mit meinem Subjektverständnis, sondern von einem «sozialreferentiellen Subjek[t]» (ebd., 22). Im 
Bildungsprozess ist das Subjekt der Bildung nicht mehr mit sich identisch, sondern wird durchdrungen von Fremdheitserfahrungen, die es permanent (de-)kontextualisieren und zu immer wieder neuen (Re-)Kontextualisierungen herausfordern.

Ausgangspunkte für die Auffassung von Bildung als einem Transformationsbegriff sind vor allem Fremdheits- und Krisenerfahrungen. Hiermit werden die Krisenerfahrungen der Moderne (vgl. u. a. Giddens 1996; Heitmeyer 1997) bezeichnet, die u. a. zu einer «Erosion tradierter Sinnbezüge» (Jörissen/Marotzki 2009, 16), von Wert- und Weltorientierungen oder Rollenvorbildern beitragen, diese in ihrer Zeitlichkeit und Kontingenz sichtbar machen und Unsicherheit kultivieren.

Die Serien 24 und Sleeper Cell bieten sich vor diesem Hintergrund zur Erforschung von Bildungsprozessen an, denn das Leben in Zeiten akuter globaler Terrorbedrohung ist eine durchgehende Fremdheits- und Krisenerfahrung. Die Prozesse der Be- oder Verarbeitung subsumtionsresistenter Erfahrungen fordert die ästhetischen Figuren zu einer konstanten Veränderung von Grund legenden Figuren ihres je gegebenen Welt- und Selbstentwurfs auf. Konflikthaft wird dies v. a. in solchen Situationen, in denen die Wert- und Normsysteme der sozialen Welt mit den Anforderungen der dauerhaft terroristisch bedrohten Wirklichkeit konfrontiert werden. Aus den daraus resultierenden Aushandlungsprozessen entstehen die performativen Bildungsgeschichten der behandelten Serien hinsichtlich des gesellschaftlichen, kulturellen und individuellen Umgangs mit Terrorismus.

Unsicherheit und Unbestimmtheit werden im Kontext von Bildungsprozessen nicht in Sicherheit und Bestimmtheit überführt, "die Relativität und Vorläufigkeit der eigenen Weltsicht ist [...] [hierbei] von Anfang an enthalten. Wir bezeichnen diese Art des suchenden, immer unter dem Vorbehalt des 〈Als-Ob〉 agierenden Selbstund Weltverhältnisses als Tentativität» [Hervorhebung im Original - MSK] (ebd., 19). Bildung erfordert vor diesem Hintergrund ein beständiges Aufs-Spiel-Setzen der eigenen Gewissheiten, ohne sich dabei selbst aufzugeben. 24 und Sleeper Cell veranschaulichen eindrucksvoll, was dies sowohl für den Einzelnen, als auch für Gemeinschaften sowie Gemeinschaftsbildungen bedeutet.

Zur Analyse der Bildungsprozesse im Kontext meiner Medienkulturanalysen beziehe ich mich auf das Modell Strukturaler Medienbildung von Jörissen/Marotzki (2009, 30ff. und 60ff.), konkret auf deren Unterscheidung in der medialen Darbietung von

- Wissensbezug (u. a. Reflexion auf Bedingungen und Grenzen von Wissensbeständen über bestimmte Wirklichkeitsgebiete);

- Handlungsbezug (z. B. Reflexion auf die Komplexität von Handlungs- und Entscheidungsoptionen in sozialen sowie individuellen Situationen);

- Grenzbezug (etwa Reflexion auf die Komplexität von Grenzen, Grenzsituationen und Grenzüberschreitungen der Selbst- und Weltorientierung);

- Biographiebezug (vor allem Reflexion auf die eigenen Identitäts- und Biographisierungsprozesse). 


\section{$24^{5}$}

24 thematisiert Versuche der Vereinigten Staaten, terroristische Angriffe abzuwenden (vgl. u. a. Desmond 2011). Das Zentrum, zumindest in den ersten sechs Staffeln, ist die Counter Terrorist Unit (CTU), eine fiktiven Anti-Terror-Einheit des CIA in Los Angeles.

Jede Staffel (1-8) umfasst 24 Episoden und fokussiert den Terror-Kampf jeweils auf einen Tag, also 24 Stunden. Dies führt einerseits die (scheinbare) Effizienz der Terror-Bekämpfung in den USA vor, andererseits enden die Staffeln offen und kündigen als direkte Übergabe zur nächsten eine neue Bedrohung an. Die Terrorbedrohung ist zugleich latent und manifest, der Ausnahmezustand die Regel, Angst Bürgerpflicht.

In 24 dominiert eine fatal-patriotische Entschlossenheit die Terrorunterhaltung, die durch die Figur des heroisch-patriotischen CTU-Agenten Jack Bauer (gespielt von Kiefer Sutherland) verkörpert und durch Folter-Marathons, Non-Stop-Gesetzesbrüche, Lynchjustiz zum Nachspielen, Selbstopferungspathos und Töten für die (nationale) Freiheit in Szene gesetzt wird. Das Ziel seines Handelns besteht darin, Anschläge mit atomaren, biologischen und chemischen Waffen abzuwehren. Verwoben in die Terrorakte sind zumeist Akteure und Regierungen aus dem Nahen Osten, Russland und China, in der siebten Staffel (2009) auch aus Afrika. Die Serie fokussiert sich in den einzelnen Staffeln einerseits auf (innen- und aussen-)politische Dauerkonflikte der USA und diskutiert diese andererseits anhand von jeweils aktuellen politischen Krisensituationen. Die Gesetzesüberschreitungen von Bauer werden in 24 letztlich als legitim und als unvermeidbare Konsequenzen, die der Patriot Act mit sich bringt, dargestellt. Die massiven Einschränkungen der amerikanischen Bürger- und Freiheitsrechte müssen hierbei zugunsten von Sicherheit geopfert werden.

Der Kampf gegen den Terror ist in 24 zudem ein technologisch hochgerüsteter. Insofern wird der Zuschauer massiv mit Technologien der Macht konfrontiert. Der Kampf gegen den Terror ist ohne Computer, Satelliten, Handys, Überwachungskameras und digitale Netzwerke nicht möglich (vgl. Patriot Act 2001, Sec. 105). Für eine Kritik am Entstehen einer - in Folge des Patriot Act - Kontroll- und Überwachungsgesellschaft gibt es entsprechend keinen Raum in 24. Meine Themen Terrorbildung und Terror-Pädagogik veranschauliche ich durch zwei Themenschwerpunkte: den Kampf gegen den Terror und damit einhergehend die Legitimation von Folter.

5 Ich beziehe mich ausschliesslich auf die zweite Staffel (2004). 


\section{Inhalt und Repräsentation}

Die Terrorzelle Second Wave, die vom Terroristen Syed Ali (gespielt von Francesco Quinn) angeführt wird, hat eine (russische) Atombombe in die USA geschmuggelt und plant, diese innerhalb von 24 Stunden explodieren zu lassen. Jack Bauer wird vom Präsidenten der USA David Palmer (gespielt von Dennis Haysbert) gebeten, die drohende Zündung einer Atombombe über Los Angeles zu verhindern. Die Atombombe wird am Flughafen in Los Angeles gefunden, kann aber nicht mehr entschärft werden. George Mason (gespielt von Xander Berkeley), der Leiter der CTU, steht durch den Kontakt mit Plutonium bei einem Ermittlungseinsatz kurz vor dem Tode und fliegt die Bombe in die Wüste, wo sie, ohne grösseren Schaden zu erzeugen, explodiert.

Die Serienhandlung ist hiermit nicht beendet, sondern bekommt eine neue Wendung. Durch einen Gesprächsmitschnitt, der der CTU zugespielt wurde, kommen drei Staaten aus dem Nahen Osten in Verdacht, ein Bündnis mit Syed Ali eingegangen zu haben und am Anschlag beteiligt zu sein. Die Konsequenz hieraus ist, dass ein Vergeltungsschlag gegen diese Staaten geplant wird. Bauer findet jedoch heraus, dass der Gesprächsmitschnitt eine Fälschung ist, die von einer Gruppe von Erdöl-Industriellen unter der Führung von Peter Kingsley (gespielt von Tobin Bell) erstellt wurde. Bauer unterrichtet den Präsidenten hierüber, worauf Palmer den geplanten Militärschlag nicht mehr durchführen will. Diese Haltung stösst auf das Missfallen vom Vize-Präsidenten Jim Prescott (gespielt von Alan Dale) und seinem Berater Mike Novick (gespielt von Jude Ciccolella), der den Präsidenten unter Berufung auf den 25. Zusatzartikel zur Verfassung der Vereinigten Staaten für amtsunfähig erklären lässt, wodurch dieser kurzfristig aus dem Amt enthoben wird - am Ende der Staffel aber sein Amt zurückerhält. Die Kriegsvorbereitungen werden im Anschluss an die Amtsenthebung fortgesetzt. Am Ende der Staffel gelingt es Bauer, die Gruppe der Verschwörer, die wesentlich aus der Wirtschaft und Politik stammen, ausfindig zu machen, sie auszuschalten und einen Krieg zu verhindern.

\section{Terror | Kampf gegen den Terror}

24 zeichnet sich durch eine deutliche Bezugnahme auf Passagen aus dem USA Patriot Act aus, der am 25.10.2001 vom Kongress im Kontext des Krieges gegen den Terror, dem wesentlichen politischen Programm der ehemaligen US-Administration unter George W. Bush, verabschiedet wurde. Der USA Patriot Act hat die Aufgabe «[t]o deter and punish terrorist acts in the United States and around the world, to enhance law enforcement investigatory tools, and for other purposes» (Patroit Act 2001). Es handelt sich hierbei um ein Bundesgesetz, das eine direkte Reaktion auf die Terroranschläge vom 11. September 2001 darstellt. Der Patriot

6 Vgl. hierzu das Kapitel 2 «America under Siege: Terrorism, Globalisation and the Politics of (American) Morality» in Peacock (2007, 73-145). 
Act definiert Terror basal als «acts dangerous to human life that are a violation of the criminal laws of the United States or of any State» (Patroit Act 2001, SEC 801: a, 5, A). Entsprechend gibt es in 24 keine explizite Terror-Definition. Terror ist alles, was die gesellschaftliche, wirtschaftliche, politische usw. Ordnung der USA gefährdet bzw. zu subvertieren droht. Die Terror-Inszenierung von 24 fokussiert sich auf drei Motivkreise:

- erstens, die Ideologie der Terroristen (islamische Fundamentalisten). Hier dominiert der Hass auf die USA; Rache für Leid und Erniedrigungen, das den Muslimen durch die USA angetan wird; und religiöser Fundamentalismus - so wird in der Staffel wiederholt von den islamischen Fundamentalisten betont, Allahs Willen zu erfüllen.

- zweitens, die Intention und Ideologie der Hintermänner aus der Politik und aus Regierungskreisen: Macht (innenpolitisch/aussenpolitisch), Konservatismus und Patriotismus.

- drittens, die Intention der Hintermänner aus der Wirtschaft: Geld und Macht zu bekommen. Das Ziel des Terroranschlags besteht letztlich darin, das Geschäftsleute aus der Ölindustrie einen Krieg der USA gegen den Nahen Osten bewirken wollen, damit die Ölpreise auf Jahre hin dramatisch ansteigen und sie dadurch hohe ökonomische Gewinne und eine daraus resultierende politische Machtposition in den USA bekommen.

Im Kampf gegen den Terror treten in 24 v. a. zwei Personen in den Vordergrund: Jack Bauer und Präsident David Palmer.

- Die Figur Jack Bauer stellt eine Art Personifizierung des Patriot Act dar und ist letztlich die einzig effektive Waffe gegen die Terror-Bedrohung (vgl. u.a. Miniter 2008). Sein Handeln zeigt, dass nur ein Held, der sich über das Gesetz stellt, die Gesetzlosen besiegen kann. Gleichwohl verkörpert er, mit Blick auf seine äusserlichen und psychisch/seelischen Verwundungen, den geschundentraumatisierten Kollektiv-Körper des terrorisierten Amerikas. Nicht zuletzt zeigt er, was der Terrorkampf erfordert: Märtyrer und Erlöser. Bauer ist, wie viele amerikanische Helden, einsam und gesellschaftsunfähig.

- Der Kampf gegen den Terror wird von Präsident David Palmer mit einer Politik der Stärke und Besonnenheit, durch Risikomanagement und Krisenkommunikation sowie mit einer niemals transparenten und offenen Pressearbeit geführt. Der Kampf gegen den Terror führt aus der Sicht der Produzenten, hier von Joel Surnow, zu einer Art Terror-Bildung bzw. Terror-Pädagogik:

$[R] i p p e d$ out of the Zeitgeist of what people's fears are - their paranoia that we're going to be attacked [and it] makes people look at what we're dealing with [in terms of threats to national security]. There are not a lot of measures short of extreme measures that will get it done. [...] America wants the war on terror fought by Jack Bauer. He's a patriot (Joel Surnow; zit. n. Mayer 2007). 
Surnow stellt deutlich heraus, dass 24 eine patriotische Wir-Intentionalität adressiert, die eine unbedingte Gültigkeit und eine moralische Ausschliesslichkeit besitzt. Hieraus soll ein Beitrag zur (Selbst-)Bildung der Zuschauer in der Auseinandersetzung mit dem Terrorismus entstehen. Diese (Selbst-)Bildungsprozesse, die durch die Bezugnahme auf Fremdes (Terrorismus) jenseits der Ordnung (etwa Werte und Gesetzte der US-amerikanischen Gesellschaft), in deren Denk- und Redefiguren mir meine Welt je gegeben ist, eine Veränderung von Grund legenden Figuren meines je gegebenen Welt- und Selbstentwurfs durch die Be- oder Verarbeitung subsumtionsresistenter Erfahrung bewirken (Patriot Act, Kollektiv-Angst Terrorismus usw.), ist aus dieser Perspektive nicht in dem von mir verwendeten Verständnis emanzipatorisch, weil 24 die richtige Terror-Deutung für sich beansprucht und deutlich (moralisch) vorgibt, welche Haltung der patriotische Amerikaner zur Terror-Bewältigung und zum Kampf gegen den Terror einzunehmen hat. 24 liefert als eine Verbindlichkeit beanspruchende Welterklärung, die nicht diskutierbar ist, sondern als unmittelbar richtig anerkannt werden muss.

We love to torture terrorists. It's good for you!?

|Joel Surnow|

\section{Folter | Legitimation von Folter}

Das wesentliche Mittel zur Terrorbekämpfung ist neben dem Einsatz von Technik das Foltern (vgl. allgemein zum Zusammenhang von Folter und serieller Erzählung Wünsch 2013). Durch Folter wird gezielt und gewaltsam psychisches oder physisches Leid zugefügt, mit dem Ziel, einen bestimmten Zweck zu erreichen, etwa ein Geständnis oder den Willen und Widerstand des Gefolterten zu brechen.

In 24 gibt es keine explizite Folter-Definition. Folter erscheint ausschliesslich als eine legitimierte Verhörtechnik in Notsituationen. In 24 gibt es allerdings nur Notsituationen, weil der Ausnahmezustand (Terrorbedrohung) zum Alltag geworden ist und daher Folter als eine wiederkehrende Form soziales Handelns im Alltag dargestellt wird. Foltern wird einerseits offiziell nicht als legitim bezeichnet, aber inoffiziell als notwendig erachtet, um die Terrorbedrohung abzuwenden.

Diese Unbestimmtheit der Folter-Definition lässt einerseits die Position der Produzenten weniger (an-)greifbar erscheinen, wie auch beim Terror, andererseits besteht so mehr Raum für das eigensinnige Sinnbasteln der Zuschauer - hier öffnet sich ein Raum für emanzipatorische und transformatorische (Selbst-)Bildungsprozese. Das Ziel der Folter besteht in 24 ausschliesslich darin, das gilt für die Terroristen genauso wie für Jack Bauer und anderer Regierungsvertreter oder -organisationen, ein Geständnis zu erzielen.

7 Zit. n. http://readroger.hbook.com/2007/02/dammit-chloe-take-two.html (zuletzt aufgerufen am 28.04.2016). 
Gefoltert wird stets auf extrem brutale Weisen - und Foltern wird visuell immer ausführlich dargestellt, damit man das Foltern in aller Ausführlichkeit betrachten kann: Säure; Streckbank; Schnitte ins Fleisch oder in Wunden; Elektroschocks; Schläge; Säge; Messer; Skalpell; Bohrmaschine, Fliesenschleifer; die Androhung, die Familie von Syed Ali, v. a. aber seiner Kinder, vor laufender Kamera töten und inn dabei zusehen zu lassen; Knochenbrechen; Androhung von physicher Gewalt; Schmerzmittel u.v.m. Gefoltert wird in 24 auch stets nur von Experten, die wissen, was es heisst, Schmerzen zuzufügen und dadurch Geständnisse in kürzester Zeit zu erhalten.

Jede Diskussion über die Rechtmässigkeit der Folter wird schnell als nicht Ziel führend unterbunden. Die Verbote zu foltern, die Präsident Palmer gegenüber Bauer äussert, werden von diesem kontinuierlich zurückgewiesen bzw. nicht beachtet, weil Bauer der Auffassung ist, dass Folter notwendig und legitim ist, um Amerika vor der Terrorbedrohung zu schützen. Terroristen haben aus der Perspektive von Bauer keine Bürgerrechte und ihnen steht keine menschenwürdige Behandlung zu, weil sie sich ausserhalb der Ordnung der Gesellschaft gestellt haben und unmenschliche Handlungen vollziehen wollen. Bauer ist bezeichnenderweise der, der am meisten foltert, und zugleich der Einzige, der der Folter widersteht und seine Peiniger zur Strecke bringt - gerade, weil er das Symbol der Gerechtigkeit und der bedingungslosen Entschlossenheit des Kampfes gegen den Terror zum Wohle Amerikas ist. Wichtig für seine Figurenwahrnehmung ist aber nicht nur seine Entschlossenheit beim Foltern und sein dem Foltern Widerstehen, sondern gerade auch die kontinuierliche Betonung seines Unbehagens am Foltern - eigentlich möchte er nicht foltern, aber hinsichtlich des Erhalts der inneren Ordnung wird er dazu gezwungen.

Folter wird hierbei zu einer legitimen und pädagogischen Folter-Unterhaltung, die immer auch in Korrespondenz zur Angst-Lust der Zuschauer steht, wie Joel Surnow verdeutlicht:

We've had all of these torture experts come by recently, and they say, ¿You don't realize how many people are affected by this. Be careful.) They say torture doesn't work. But I don't believe that. I don't think it's honest to say that if someone you love was being held, and you had five minutes to save them, you wouldn't do it. Tell me, what would you do? If someone had one of my children, or my wife, I would hope I'd do it. There is nothing - nothing - I wouldn't do [Hervorhebung im Original - MSK] (Joel Surnow; zit. n. Mayer 2007).

Folter wird in 24 nicht rational legitimiert, wie diese Aussage anschaulich macht, sondern affektiv, emotional, suggestiv und moralisch. Vor diesem Hintergrund wird Foltern normalisiert und gehört notwendig zur Terror-Bekämpfung, Terror-Deutung und sozialen Gewöhnung an den Terror. Durch die mimetische Übersetzung dieser 
Haltung erhält das Foltern in 24 eine diskurslegitimierende, diskursstabilisierende und eine diskursirritierende Wirkung.

\section{Sleeper Cell}

Sleeper Cell setzt, wie 24, Amerikas Terrorangst in Szene. Im Unterschied zu 24, versucht Sleeper Cell sich mit politisch korrektem und pädagogisch wertvollem mood management sowie mit einer (scheinbar) individualpsychologischen Perspektive am Kampf gegen den Terror zu beteiligen, Deutungshoheit über den Terror sowie über die Produktion von Terrorbildern und über die Terror-Bildung zu erlangen. ${ }^{8}$ Sleeper Cell will den Willen zur Ausgewogenheit, Multiperspektivität und eine differenzierte Ordnung der ethnisch-religiösen sowie terroristischen Wirklichkeit ins Zentrum rücken, ebenso wie ein Plädoyer für interkulturelle Toleranz.

\section{Inhalt und Repräsentation}

Eine Terrorzelle plant Anschläge auf Los Angeles. Niemand weiss, wann und wo sie zuschlagen will. Mögliche Ziele sind u. a. der Flughafen, ein Atomkraftwerk, ein Einkaufszentrum, ein Footballstadium. Universitäten werden ausgespart, wie der Kopf der Terrorzelle, Faris «Farik〉 al-Farik (gespielt von Oded Fehr), betont, der in Los Angeles unter jüdischer Scheinidentität ein Sicherheitsunternehmen leitet. Der Grund hierfür liege darin, dass es dort zu viele potentielle Sympathisanten gebe. Letztendlich ist ein Giftgasanschlag im vollbesetzten Dodger Baseball-Stadion geplant.

Der afroamerikanische FBI-Agent Darwyn al-Sayeed (gespielt von Michael Ealy), selbst praktizierender Muslim, hat den Auftrag, die Schläferzelle zu infiltrieren, um Insider-Informationen zu den geplanten Terroranschlägen zu beschaffen. Problematisch hierbei ist, dass er kaum in der Lage ist, die notwendigen Informationen zu beschaffen, denn Farik weiht die Mitglieder der Terrorzelle immer erst kurz vorher den Aktionen ein.

Das Ziel des Undercover-Einsatzes besteht darin, die Terrorzelle, wie Darwyn gegenüber seinem FBI-Kontaktmann Special Agent Ray Fuller (gespielt von James LeGros) äussert, endgültig auszulöschen und nicht durch vorschnelles Eingreifen zu riskieren, dass dieses Ziel nicht realisiert werden kann. Dieses Statement korrespondiert der wiederholt von George W. Bush und anderen (europäischen) Politikern vorgebrachte Rhetorik, den Terror so lange und mit allen notwendigen Mitteln zu bekämpfen, bis er endgültig besiegt sei. Das dies eine Sisyphus-Aufgabe ist, haben die fünfzehn Jahre nach 9/11 verdeutlicht.

8 Ich beziehe mich ausschliesslich auf die 1. Staffel (2005), die den bezeichnenden Untertitel «Friends. Neighbors. Husbands. Terrorists» trägt. Ich verwende die deutsche DVD-Box (4 DVDs. Paramount Home Entertainment 2009). 


\section{Terror | Kampf gegen den Terror}

Ungewöhnlich für eine US-Produktion ist, dass nicht nur die Terroristen Muslime sind, sondern auch einer der Gesetzesvertreter bzw. der Protagonist der Guten. Seit den Anschlägen von 9/11 gibt es für muslimische Charaktere in Amerika zumeist nur eine Rolle.

Je tiefer Darwyn in die Terrorzelle eindringt, desto mehr muss er Gesetzte brechen, mit ansehen, wie Unschuldige kaltblütig ermordet werden, und ist gezwungen, selbst zum Mörder zu werden - mit dem gleichen Schicksal ist Jack Bauer in 24 konfrontiert. So erschiesst er ein Mitglied der Terrorzelle, um ihn vor den unmenschlichen Qualen der Steinigung zu bewahren. Dies war die Strafe, die Farik über ihn verhängt hat, weil er über die glorreichen Taten der Terrorzelle bei einem Verwandten in Ägypten am Telefon geprahlt hatte und damit den Erfolg der Terrorzelle riskierte.

Die Terrorzelle ist multikulturell, die einzigen beiden Verbindungen zwischen den Extremisten bestehen darin, dass sie alle eine militärische Ausbildung haben und ganz normale Berufe ausüben, sozial verträglich leben. Die islamischen Terroristen haben sich scheinbar perfekt in die westliche Gesellschaft eingefügt. Neben Farik, Darwyn und dem getöteten Verräter Bobby (gespielt von Grant Heslov), gehören noch der Franzose Christian Aumont (gespielt von Alex Nesic), ein Ex-Skinhead, der Bosnier Ilija Korjenic (gespielt von Henri Lubatti) und der blauäugige, blonde Amerikaner Tommy Emerson (gespielt von Blake Shields), Sohn von wohlhabenden Liberalen, dessen Mutter eine Berkeley-Professorin ist.

Eine Serie über den Dschihad, in dem kaum Saudis und Syrer, kaum Pakistaner und Iraker mitspielen. Hiermit wird darauf hingewiesen, dass der islamistische Terror längst in der Mitte der westlichen Gesellschaft Unterstützung gefunden hat. Buß (2008) betont hierzu:

Penibel zeichnen die beiden Chefautoren Ethan Reiff und Cyrus Voris in «Sleeper Cell〉 die Verkehrswege und Umschlagplätze des islamistischen Terrors nach - und zeigen dabei, dass deren Zerschlagung kaum mit rethnic profilingy, also mit der kriminalistischen Katalogisierung nach Herkunftsmerkmalen, gelingen dürfte. Den bärtigen Mudschahidin sucht man in dieser hoch gerüsteten und kompliziert vernetzten Terroreinheit umsonst. Zu unterschiedlich ist die kulturelle Identität der sogenannten Gotteskrieger, zu unterschiedlich ihre Motivation.

Das Gegenteil gilt fast immer für 24.

Terroristen als Alltagsmenschen und die alltägliche Lebenswelt als Rückzugsort für Terroristen. Besser können Kollektiv-Ängste, Verdächtigungsszenarien sowie Denunziationsrituale audiovisuell nicht in Bewegung gesetzt werden. In 24 wird dieses Bedrohungsszenario noch potenziert, denn hier sind, neben den Alltagsmenschen, auch die Politik und Wirtschaft immer in die Terroraktivitäten involviert, 
allerdings nur aus machtpolitischen und ökonomischen Gründen. Es scheint also kein Jenseits der terrordurchtränkten (amerikanischen) Gegenwartsgesellschaft zu geben. Abgesehen vom ultra-patriotischem Handeln Jack Bauers, der in Anbetracht aller Abgründe allein durch den Glauben an die Werte seiner Nation den Terror, zumindest zeitweise, in die Knie zwingen kann. In dieser Hinsicht bleibt 24 konsequent, weil letztlich diese patriotische Entschlossenheit in ihrem Zentrum steht.

Kompensiert werden soll diese Terrormanie in Sleeper Cell einerseits durch die Aufklärung über die Motive und Hintergründe der Täter, also Einblicke in ihre menschliche-allzumenschliche Seite, und andererseits durch Aufklärung über den Unterschied zwischen den verschiedenen Religionen, kulturellen Eigenheiten und einer Kartographie des Guten sowie Bösen.

Dieses Vorhaben erschöpft sich sehr schnell, denn dem Zuschauer werden wiederholt extrem allgemeine Erörterungen dieser Themen präsentiert sowie Erklärungen angeboten, die allesamt bekannt und in unterschiedlichsten Kontexten immer wieder geäussert wurden bzw. werden. Ein differenziertes Mehr an Wissen bzw. Emanzipation wird nicht erzielt, dies zeigen etwa die den Terroristen zugeschriebenen ideologischen Handlungsmotive.

Die v. a. sprachliche Inszenierung der ideologischen Basis der Terror-Zelle, aus der die eigensinnige Terror-Bildung entsteht, lässt sich durch acht Grundzüge charakterisieren:

1. «Gesetze, die der Mensch macht, sind die des Teufels. Nur das Gesetz Gottes ist gerecht. Finde schnell zum Ziel. Hier ist der Schlüssel zu Deiner höheren Bestimmung», so der Bibliothekar der Gefängnisbibliothek zu Darwyn (Episode 1, 0:23:27 - 0:23:58).

2. Zur Durchsetzung des Willens und der Gesetze Gottes braucht es entschlossene Krieger bzw. Märtyrer: «lch stelle ein Team von Heiligen Kriegern zusammen, von Gläubigen, die bereit sind, ohne Vorwarnung und ohne Erbarmen zuzuschlagen», verkündet Farik gegenüber Darwyn (Episode 2, 0:14:54 - 0:15:12).

3. Die Durchsetzung kann nur gewaltbasiert erfolgen: Farik: «Wo liegt das Paradies Gottes?» Darwyn: «Es liegt im Schatten des Schwertes» (Episode 1, 0:33:11 - 0:23:22).

4. Diese Auslegung des Korans lehnt Darwyn entschieden ab, in dem er zu seinem FBI-Kontaktmann sagt: «Diese Leute haben nichts mit meinem Glauben zu tun» (Episode 1, 0:19:27 - 0:20:02).

5. Zudem spricht er von ihnen als «Hardcore-Psychopathen» (Episode 2, 0:07:13 0:07:16). Von einem Mitglied der Terrorzelle wird ihm zudem vorgehalten: «Die meisten Araber halten Schwarze nicht für richtige Moslems» (Episode 2, 0:37:10 - 0:37:18). Darwyn gibt entsprechend durch sein Verhalten eine Einführung in die Sitten und Gebräuche des Islam und möchte seine ignoranten Mitbürger 
immer wieder aufklären, dass nicht jeder Muslim ein Islamist ist und was die wahren Grundsätze des Islam sind. Bei aller positiven Darstellung des richtigen Islamverständnisses, wird in Sleeper Cell aber fälschlicherweise Islamismus mit Terrorismus immer wieder gleichgesetzt.

6. Die Aussenpolitik der USA, z. B. die Verwicklung des CIA in Afghanistan, oder das Versagen der UN in Ex-Jugoslawien.

7. Der Sitten- und Werteverfall der amerikanischen Gesellschaft, stellvertretend für die westliche Welt, in der etwa Drogen, Alkohol, Sex und Gewalt das Leben bestimmen. In diesem Kontext wird auch der Ehrenmord an einem jungen islamischen Mädchen, der von ihrem eigenen Vater in Auftrag gegeben wurde, legitimiert, weil sie einen amerikanischen Freund hatte und sich heimlich mit inm traf. Auch Darwyn wird von einem Mitglied der Terrorzelle vorgeworfen, ein Verhältnis mit Gayle zu haben: «Du schläfst mit einer Ungläubigen?» (Episode 2, 0:13:56 - 0:14:12).

8. Letztlich spielt die Terror-lkonografie und -Mythenbildung eine entscheidende Rolle: So sagt ein Mitglied der Terrorzelle zu Darwyn: «Farik traut niemanden, außer vielleicht Osama» (Episode 1, 0:17:09 - 0:17:14).

Diese Aspekte sind prinzipiell nicht fiktiv, dennoch bleibt Sleeper Cell aber bei ihrer blossen Benennung stehen - das Gleiche gilt für 24. Dies kann als die politischpolitisierende Haltung der Serie, genauso wie bei 24, bezeichnet werden. Eine durch die Serien-PR angekündigte individualpsychologische und multiperspektivische Betrachtungsweise kann somit überhaupt nicht stattfinden, ebenso wenig transformatorische (Selbst-)Bildungsprozesse angeregt werden.

Ein wesentlicher (fernsehmedialer) Grund für diesen Aspekt besteht darin, dass die Organisation und Ordnung sowie der Zusammenhang und -halt des Fernsehens mit der Zeitfigur der Serie beschrieben werden kann:

Im Konzept der Serie [...] denkt das Fernsehen über die Wiederholung als notwendige Strukturgebung im Reich der Ereignis gewordenen Bilder nach, das das Fernsehen ist. Serien verknüpfen nicht nur Ereignisse nach bestimmten Schemata miteinander, machen sie dadurch erwartbar und erinnerbar und verleihen den Ereignisketten eine je spezifische Identität, sondern sie reflektieren diese Verknüpfungen und Varianten, machen sie sichtbar (Fahle/ Engell 2006, 17).

Die Serialität der Performativität der Terrorbildung in 24 und Sleeper Cell führt in den einzelnen Staffelfolgen und von Staffel zu Staffel zu einer hohen inszenatorischen sowie kommunikativen Redundanz, die v. a. durch das Serienformat erzeugt wird (seriell bedingte Wiederholung). Gleichzeitig besteht in dieser Formatgrenze der Fernsehserie eine grosse Variabilität an Aneignungs-, Bildungs- und Kommunikationsmöglichkeiten. Das Serienformat formatiert so die Serienhandlung und die von ihr ausgehenden möglichen Medienbildungsprozesse. Zugleich versuchen 
sich die beiden Serien 24 und Sleeper Cell in ihren Terror-(Bildungs-)Erzählungen dieser Formatierung zu entziehen, indem sie der seriell-redundanten Terror-Erzählung eine höhere kommunikative und intellektuelle Komplexität gegenüberstellen, um damit das herkömmliche serielle Format der Fernsehserie bedingt zu subvertieren (seriell bedingte Variation).

Das Fernsehen kann hier ein

privilegierte[r] Ort der populären, interdiskursiven Wissensproduktion [sein]: Das Fernsehen greift selektiv auf die verschiedensten Wissensbeständen und Ansichten einer Gesellschaft zu und übersetzt diese - auch Angesichts der Unbekanntheit des Publikums - meist in allgemein verständliche und prägnante Bilder und Narrative (Stauff 2014, 310).

In den beiden Serien fungiert das Fernsehen als ein kulturelles Forum der Unterhaltung, Wissensvermittlung und Medienbildung zugleich, vorausgesetzt, man lässt sich darauf ein. Die Performativität der Terror-Bildung bezieht sich in 24 und Sleeper Cell dabei einerseits auf die narrative Bedeutungsproduktion und Wissensvermittlung; zugleich aber andererseits auf die Eigensinnlichkeit des Fernsehbildes, d. h. auf die Reflexion der performativen Sichtbarkeit von Terrorakten, Terrorristen und Terrorbekämpfung durch das Fernsehbild. Diese serielle Performativität von Terror-Bildern fokussiert sich in beiden Serien auf stereotype Darstellungen und ist im Unterschied zu den Terror-Narrationen nicht geeignet, um Terror-Bildung instruktiv zu inszenieren. Allerdings arbeitet v. a. 24 mit drastischen Bildinszenierungen, die zumindest beim Thema Folter dessen Drastik beim Betrachten performativ werden lassen.

\section{Fazit. Terror-Bildung und Terror-Pädagogik im Zeichen der Angst}

24 und Sleeper Cell stehen symptomatisch für eine gesellschaftliche und mediale Entwicklung nach 9/11. ${ }^{9}$ Krisen (etwa Krieg, Erdbeben, Hungersnöte, Überschwemmungen, Terroranschläge) gehören zum festen Repertoire der Medienproduktionen und zur «Mediennahrung unseres Alltagslebens» (Baudrillard 1994, 108). Bolz $(1999,77)$ betont daher zu Recht: «Mit dem Wort «Krise» simplifiziert und politisiert man hohe Komplexität. Das heißt im Klartext: Die Krise ist nicht Ausnahmezustand, sondern Normalform unserer modernen Existenz.» Krise ist also immer. Das widerspricht zwar der Definition des Begriffs, aber nicht der Logik der Medien. Krisen werden in den Medien v. a. durch drei Strategien in Szene gesetzt: durch

9 Hier wird kein bestimmtes literarisch-fiktionales Genre begründet, sondern die Terror-Serien stellen ein Untergenre des Kriminalfilms dar, der Verbrechen und ihre Aufklärung behandelt. In den beiden untersuchten Serien steht die Perspektive des Ermittlers im Vordergrund, insofern gibt es hier auch Bezugspunkte zum Polizei- und Detektivfilm. In Sleeper Cell, im Unterschied zu 24, wird auch versucht, die Perspektive des Täters möglichst unabhängig von dem des Ermittlers darzustellen, daher sind bei dieser Serie auch Bezüge zum Gangsterfilm und Thriller möglich. Die Perspektive des Verbrecheropfers spielt in beiden Serien kaum eine Rolle, so dass es keine speziellen Bezüge zum Psychothriller gibt (vgl. Hickethier 2005; vgl. Stiglegger 2017). 
(1) Sensationalisierung und (2) Skandalisierung der Wirklichkeit, die zumeist mit einer drastischen $(3)$ «Angstrhetorik» (Bolz 1997, 105) thematisiert werden. Es sind gerade die Medien, die bestimmte Ängste schüren und versuchen, Kollektiv-Ängste zu generieren und zu synchronisieren, wie etwa die Angst vor dem Terrorismus. Medien versorgen uns aber nicht nur mit Informationen, die irritieren, erregen und v. a. ängstigen, sondern auch mit speziellen Ordnungs- und Sicherheitsschemata, die stabilisieren, orientieren und beruhigen: «Der strukturelle Negativismus der Massenmedien wird durch Moralisierung kompensiert. Und Moralisierung heißt konkret: Das Medien, zum Beispiel das Fernsehen, nennen Namen und zeigen Bilder als Antwort auf die Frage, warum schief läuft, was schief läuft» (ebd.) - dies trifft auf die beiden Serien ebenso zu, wie auf die Sicht der Produzenten, etwa mit Blick auf die Aussagen von Joel Surnow. Hierdurch werden zugleich mediale Sicherheits- und Gefahrräume geschaffen, die ambivalent bleiben. Ebenso muss es Personen ins Bild setzen, die dies kritisieren oder sich gegen diese Missstände engagieren - Jack Bauer und Darwyn al-Sayeed sind solche Personen.

Angst, darauf rekurrieren die beiden Serien, ist nach 9/11 zu einem Gefühlszustand, der nicht nur das private, sondern auch zunehmend das öffentliche Leben dominiert, geworden. Die (gesellschaftliche und medienkulturelle) Produktion von Angst wird zu einem produktiven Machtinstrument und zum Mittel der Legitimation von Handlungen, die gesellschaftlich eigentlich nicht legitim sind. Insofern bewegt sich 24 häufig in ethischen, juristischen und politischen Grauzonen, die die Bush-Regierung nach 9/11 durch den USA Patriot Act geschaffen hat und durch die Tabubrüche, wie das Foltern, gesellschaftsfähig werden, weil sie als patriotisch erscheinen. Sie werden gesellschaftsfähig, weil die Zukunft der Nation auf dem Spiel steht und dies nur lösbar ist durch entschlossene Taten, nicht durch Verhandeln. Hierbei kann die Ordnung stets nur wieder hergestellt werden, indem sie verletzt wird.

Andererseits fordert 24 zu einer Lektüre gegen den Strich auf, denn die 2. Staffel spielt mit dem Klischee, dass Terroristen immer aus dem Nahen Osten kommen müssten. In fast jeder Staffel sind zwar immer auch islamische Fundamentalisten in die Terrorakte verwoben, letztlich sind die Drahtzieher aber andere Akteursgruppen. Die grösste Gefahr für die USA geht letztlich von den USA, aus deren eigenen Machtzentren hervor: zumeist aus der Wirtschaft und Politik. Hiermit wird ein grundsätzliches Misstrauen gegen jene Instanzen, v. a. die Politik, kultiviert, die massgeblich für die Terror-Deutung und Terror-Bekämpfung zuständig sind und dadurch einen bedeutsamen Autoritätsverlust erleiden. Diese Perspektive adressiert transformatorische (Selbst-)Bildungsprozesse, weil sie eine Fremdheitserfahrung mit der Serie in der Serie ermöglicht, die diese nicht erklärend determinieren kann, wie dies für die grundlegende Terror-Deutung, Terror-Bewältigung und Terror-Bildung in 24 der Fall ist, sondern die sich an den Rändern der offiziellen 
Seriennarration abspielt. In Sleeper Cell sind hingegen alle Narrationsstränge transparent und werden in ihrer Vielschichtigkeit und Ambivalenz offen ausgestellt. Mit Blick auf das Modell Strukturaler Medienbildung von Jörissen/Marotzki (2009) lassen sich bei 24 und Sleeper Cell folgende mediale (Selbst-)Bildungsprozesse beobachten:

- Wissensbezug: Die Reflexion auf Bedingungen und Grenzen von Wissensbeständen über das Wirklichkeitsgebiet Terrorismus wird in 24 und Sleeper Cell von den offiziellen Wissensagenturen der Gesellschaft, hier der Regierung, bestimmt. Dieser Wissensbezug ist affirmativ und nicht transformatorisch orientiert. Wissensaneignung, Wissensausbau und Wissensanwendung sind hierbei nicht Fremdheitserfahrungen, sondern medien- und soziokulturelle Vertrautheitserfahrungen - Demonstrationen erlernten Wissens bzw. von Welterklärungen. Die im Kontext von 24 und Sleeper Cell ausgestellten Wissensformen sowie die Wissensagenturen auf die sie sich beziehen, sind autoritär und/oder Verbindlichkeit beanspruchend.

- Handlungsbezug: Die Reflexion auf die Komplexität von Handlungs- und Entscheidungsoptionen in sozialen sowie individuellen Situationen wird in meinen Beispielen von den jeweiligen Bezugsrahmen vorgegeben und stellt keine eigensinnige Modifikation dieser durch ästhetische Figuren wie z. B. Jack Bauer dar. Populäre Medienkulturen wie die Fernsehserie stellen aber Handlungsaufforderungen und Dialoge mit der Gegenwart dar, um eine möglichst selbstbestimmte Position zu den inszenierten Terror-Themen zu erhalten.

- Grenzbezug: Die Reflexion auf die Komplexität von Grenzen, Grenzsituationen und Grenzüberschreitungen der Selbst- und Weltorientierung findet in meinen Fallbeispielen durch die Auseinandersetzung mit dem Terrorismus und der Terrorismusbekämpfung als den wesentlichen Grenzerfahrungen sowie Grenzsituationen statt. Diese Grenzbezüge sind in 24 und Sleeper Cell nicht produktiv, sondern wesentlich regressiv und bewirken regide (interkulturelle) Ausschlusssysteme zwischen dem Eigenen und dem Fremden, dem Identischen (der Nation) und dem Nicht-Identischen (den Terroristen), dem Selbst (Staatsbürger) und dem Anderen (Verbrecher).

- Biographiebezug: Die Reflexion auf die eigenen Identitäts- und Biographisierungsprozesse findet in den von mir behandelten Fallbeispielen nicht statt. Im Kontext von 24 und Sleeper Cell wird der Zuschauer mit den Ergebnissen von transformatorischen Selbst- und Weltverhältnissen v.a. durch die ästhetische Figur Jack Bauer konfrontiert, aus denen aber explizit keine weiteren transformatorischen (Selbst-)Bildungsprozesse folgen.

- Der Zusammenhang von (Selbst-)Bildung und Medienbildung spielt in 24 und Sleeper Cell mit Blick auf die (Selbst-)Technologien der Macht und hinsichtlich der Produktion von Öffentlichkeit und Öffentlicher Meinung durch die 
Regierung und die Presse eine Rolle, wobei die Presse in 24 zumeist negativ dargestellt und häufig auch in ihrem Handeln eingeschränkt wird. Meinungs-, Medien- und Pressefreiheit, ebenso wie Bürger- und Freiheitsrechte spielen in 24 konsequenterweise auch keine wesentliche Rolle.

Mein Verständnis von Bildung als Prozess der Bezugnahme des Subjekts auf Welt und dem von Bildung, die sich am Subjekt vollzieht, erweist sich in den von mir diskutierten Fallbeispielen als performative Medieninszenierung einer gelingenden, wenn auch ambivalenten Biographieerzählung. Diese resultiert aus den Bildungsprozessen, die die ästhetische Figur Jack Bauer durch die Internalisierung der Werte und Normen der US-amerikanischen Gesellschaft absolviert und vorbildlich vorlebt.

Hierbei wird eine aktive Formung von Selbst und Welt adressiert, die aber, dies stellt die Ambivalenz dieser (Selbst-)Bildungsprozesse heraus, grundsätzlich fremdbestimmt wird von den Anforderungen der Bezugsrahmen, d.h. den Prinzipien der US-amerikanischen Terrorbekämpfung nach 9/11, in denen sich die ästhetischen Figuren bewegen. Aufgelöst wird diese Ambivalenz nicht, auch nicht in den Kontexten, die mit Ambivalenzen und Uneindeutigkeiten spielen, um transformatorische Fremdheits- und Krisenerfahrungen (implizit oder explizit) auszulösen, wie dies etwa hinsichtlich der Inszenierung von US-amerikanischer Politik und Wirtschaft, also der Bedrohung von Amerika durch Amerika, als die eigentlichen Initiatoren von Terrorakten.

\section{Literatur}

24. «24 - Twenty Four». 2001-2010. Regie: Surnow, Joel, und Cochran, Robert. 8 Staffeln, 192 Episoden, FOX.

24. «24 - Twenty Four, Day 2, 8:00 a.m. - 8:00 a.m.». 2004. Regie: Surnow, Joel, und Robert Cochran. 2. Staffel, 24 Episoden. Deutsche DVD-Box, 7 DVDs: Twentieth Century Fox Home Entertainment.

24: Live Another Day. 2014. Regie: Surnow, Joel, und Robert Cochran. 1 Staffel, 12. Episoden, FOX.

24. «24: Redemption». 2008. Regie: Surnow, Joel, Robert Cochran, und Jon Cassar. 1h 24min. Arp, Robert. 2016. Die Philosophie bei Homeland. Moralische und ethische Fragen im Kampf gegen den Terror. Weinheim: Wiley-VCH Verlag.

American Odyssey. 2015 -. Regie: Armus, Adam, Nora Kay Foster, und Peter Horton, 1 Staffel, 14 Episoden, NBC.

Baudrillard, Jean. 1994. Die Illusion des Endes oder Der Streik der Ereignisse. Berlin: Merve. Bolz, Norbert. 1997. Die Sinngesellschaft. Düsseldorf: ECON.

Bolz, Norbert. 1999. Die Konformisten des Andersseins. Ende der Kritik. München: Fink. 
Buttler, Martin. 2003. «Ästhetik des Terrors - Die Bilder des 11. Septembers $2001 »$. In Bilder des Terrors - Terror der Bilder? Krisenberichtserstattung am und nach dem 11. September, hrsg. v. Michael Beuthner, Joachim Buttler, Sandra Fröhlich, Irene Neverla und Stephan A. Weichert, 26-41. Köln: Herbert von Halem.

Däwes, Birgit, Alexandra Ganser, und Nicole Poppenhagen. Hrsg. 2015. Transgressive Television: Politics and Crime in 21st-Century American TV Series. Heidelberg: Universitätsverlag Winter.

Designated Survivor. 2016 -. Regie: Guggenheim, David. 1 Staffel, 22 Episoden, ABC.

Desmond, Manderson. 2011. "Trust US Justice: 24, Popular Culture and the Law». In Imagining Legality: Where Law Meets Popular Culture, hrsg. v. Austin Sarat, 22-54, Tuscaloosa: The University of Alabama Press.

Fahle, Oliver, und Lorenz Engell. 2006. «Philosophie des Fernsehens - Zur Einführung». In Philosophie des Fernsehens, hrsg. v. Dies, 7-19, München: W. Fink.

Flynn, Michael, und Fabiola F. Salek. Hrsg. 2012. Screening torture-Media Representations of State Terror and Political Domination. New York: Columbia University Press.

Hickethier, Knut. Hrsg. 2005. Kriminalfilm. Stuttgart: Reclam.

Hitzler, Ronald, und Jo Reichertz. 2003. «Die gesellschaftliche Verarbeitung von Terror». In Irritierte Ordnung. Die gesellschaftliche Verarbeitung von Terror, hrsg. v. Ronald Hitzler, Jo Reichertz, 7-9. Konstanz: UVK.

Homeland. 2011-. Regie: Gansa, Alex, und Howard Gordon. 6 Staffeln, 70 Episoden, SHOWTIME.

Jörissen, Benjamin, und Winfried Marotzki. 2009. Medienbildung. Eine Einführung. Bad Heilbrunn: Julius Klinkhardt.

Mayer, Jane. 2007. «Whatever It Takes. The Politics of Man behind «24ı». In The New Yorker, 19. Februar. http://www.newyorker.com/magazine/2007/02/19/whatever-it-takes.

Miniter, Richard. Hrsg. 2008. Jack Bauer for President. Terrorism and Politics in 24. Dallas: BenBella Books.

Newcomb, Horace, und Paul M. Hirsch. 1986. «Fernsehen als kulturelles Forum. Neue Perspektiven für die Medienforschung». In Rundfunk und Fernsehen, 2: 177-190.

[Patroit Act 2001] United States Government Printing Office, und United States: National Archives and Records Administration: Office of the Federal Register. 2001. An Act to Deter and Punish Terrorist Acts in the United States and around the World, to Enhance Law Enforcement Investigatory Tools, and for Other Purposes. Bd. H.R. 3162. http:// www.gpo.gov/fdsys/pkg/PLAW-107publ56/content-detail.html.

Person of Interest. 2011-2016. Regie: Nolan, Jonathan. 5 Staffeln, 103 Episoden, CBS.

Peacock, Steven. Hrsg. 2007. Reading 24. New York. I.B. Tauris.

Schneckener, Ulrich. 2006. Transnationaler Terrorismus. Charakter und Hintergründe des «neuen〉 Terrorismus. Frankfurt/M.: Suhrkamp.

Schuster, Thomas. 2001. «Phantom des Terrors. Die Gewalt im Zeitalter ihrer medialen Potenzierbarkeit». In Frankfurter Allgemeine Zeitung, 18. September: o. S.

Sleeper Cell. 2005-2006. Regie: Reiff, Ethan, und Cyrus Voris. 2 Staffeln, 18 Episoden, Showtime Networks.

Sleeper Cell. «Friends. Neighbors. Husbands. Terrorists». 2005. Regie: Reiff, Ethan, Cyrus Voris, und Clark Johnson. 1. Staffel, 10 Episoden, Deutsche DVD-Box, 4 DVDs. Paramount Home Entertainment. 
Sleeper Cell. «Episode 1: Al-Faitha». zuerst gesendet am 4. Dezember 2005 auf Showtime Networks. 54 Minuten. Regie: Reiff, Ethan, Cyrus Voris, und Clark Johnson. DVD: Paramount Home Entertainment.

Sleeper Cell. «Episode 2: Target». zuerst gesendet am 5. Dezember 2005 auf Showtime Networks. 51 Minuten. Regie: Reiff, Ethan, Cyrus Voris, und Guy Ferland. DVD: Paramount Home Entertainment.

Stauff, Markus. 2014. «Fernsehen/Video/DVD». In Handbuch Medienwissenschaft, hrsg. v. Jens Schröter, 307-315, Stuttgart/Weimar.

Stiglegger, Marcus. 2010. Terrorkino: Angst/Lust und Körperhorror. Berlin: Bertz+Fischer.

Stiglegger, Marcus. 2017. "Genrekino». In Handbuch Popkultur, hrsg. v. Marcus S. Kleiner und Marcus Stiglegger, Stuttgart/Weimar: J. B. Metzler Verlag (im Erscheinen).

Strike Back. 2010-2015. Regie: Bassett, Michael J., Chris Ryan, und andere. 5 Staffeln, 47 Episoden. BBC Worldwide.

Takacs, Stacy. 2012. Terrorism TV. Popular entertainment in Post-9/11 America. Lawrence: University Press of Kansas.

The Unit - Eine Frage der Ehre. 2006-2009. Regie: Mamet, David. 4 Staffeln, 70 Episoden. CBS.

Wünsch, Michaela. 2013. «Folter und die Zeitlichkeit des Traumas im serial drama». In Folterbilder und -narrationen. Verhältnisse zwischen Fiktion und Wirklichkeit, hrsg. v. Julia Bee, Reinhold Görling, Johannes Kruse und Elke Mühlleitner, 173-186, Göttingen: Vandenhoeck \& Ruprecht. 